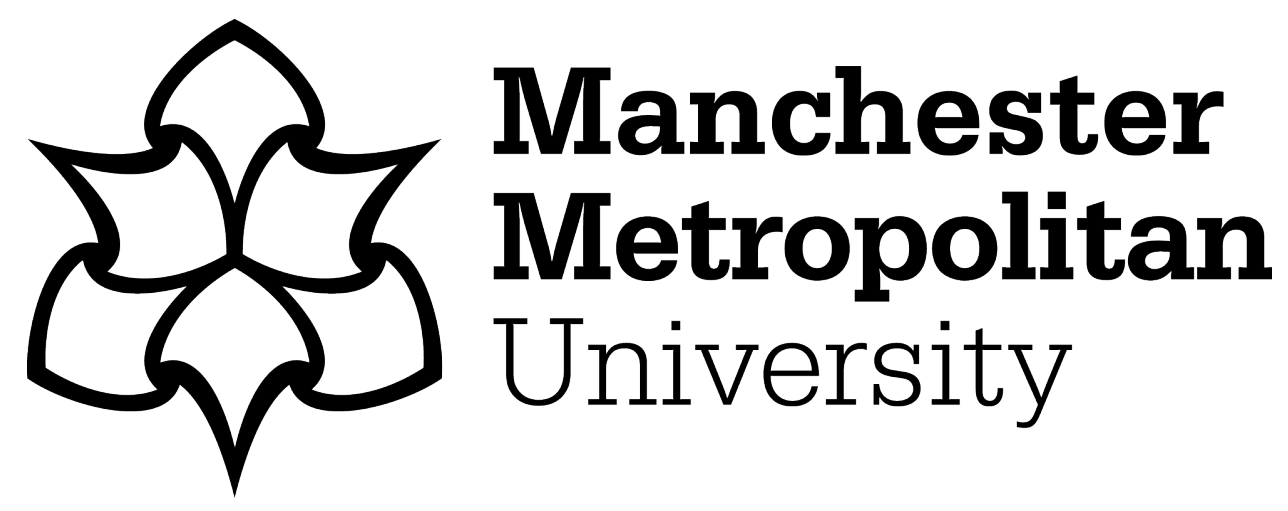

Rowsell, Jennifer, Burke, Anne, Flewitt, Rosie ORCID logoORCID: https://orcid.org/0000-0003-1986-0644, Liao, Han-Teng, Lin, Angel, Marsh, Jackie, Mills, Kathy, Prinsloo, Mastin, Rowe, Deborah and Wohlwend, Karen (2016) Humanizing Digital Literacies: A Road Trip in Search of Wisdom and Insight. The Reading Teacher: a journal of the International Reading Association, 70 (1). pp. 121-129. ISSN 0034-0561

Downloaded from: https://e-space.mmu.ac.uk/624156/

Version: Accepted Version

Publisher: International Reading Association

DOI: https://doi.org/10.1002/trtr.1501

Please cite the published version 
Preprint

\section{Humanizing Digital Literacies: A Roadtrip in Search of Wisdom and Insight}

Jennifer Rowsell with contributions from Anne Burke, Rosie Flewitt, Angel Lin, Jackie

Marsh, Kathy Mills, Mastin Prinsloo, Deborah Rowe, and Karen Wohlwend

\section{Introduction}

Children do so many things with technology - they swipe, trace, drag, tap, turn up and down the volume, click, enlarge, read, make videos and they need little to no assistance to do so. The truth about digital literacies is that they are so tied up with being human that they imply different things for different people. In this column, I embark on a road trip to showcase how international researchers in early childhood literacy take up the notion of digital literacies in all of its diversity.

The trouble with generalized notions of digital literacies is that they render the ways that we communicate and make meaning through technologies as universal in nature and as equal in access. This is not the case; not everyone has technology and those who do use technologies use them in a multitude of ways. Our relationships with technology are always in a state of becoming (Ellsworth, 2005). While some people are devoted to technology, other people use it intermittently and some people fear or even vilify it. Digital literacies are many things all at once: highly visible; globally dispersed; differentially proportioned; socially participatory; not to mention that they make us think in a multitude of ways. 
Preprint

Given the connected, mobile nature of many technologies, they can be regarded as placeless and context-free when in fact, like all things and people, technologies are informed by contexts as much as contexts are informed by technologies. Prinsloo (2005) recommends a view of technologies as placed resources in order to avoid universalizing the contexts where they are used. Prinsloo speaks specifically of new literacies scholars who tend "to treat as given the processes of signification and meaning-making involved, which on closer examination turn out to be considerably more complex and variable than they suggest" (p. 89). The notion of place-based technologies fosters an awareness that technologies may be pervasive but the specific types of devices are variable, which of course can result in different kinds of reading and writing practices with varying degrees of currency.

With a hope of localizing and humanizing digital literacies, I set out on a journey to visit different scholars around the world to garner wisdom and insight from their research. My criteria for choosing these eight scholars rest on: their work in the area of early childhood literacy; their situated accounts of digital literacies; and their spectrum of perspectives. Needless to say, it is not a thorough and comprehensive review, but instead these are telling examples of contextually informed work across varied populations. I offer these brief vignettes to tease out a series of challenges for literacy educators and to set an agenda for further conversations and developments in the field.

\section{A Digital Literacies Roadtrip}

I began my trip with Dr. Karen Wohlwend whose widely cited work on popular culture and new media offers a particular lens on digital literacies ...

\section{USA: Play Literacies with Toys, Popular Media, and iPad Puppets}

Karen Wohlwend, Indiana University, USA

In my research, I explore literacies that move beyond print, seeking to better understand how teachers might update literacy curricula to provide a space where young children can draw upon their cultural repertoires and imaginative play experiences. How should teaching expand for young learners who think in $3 \mathrm{D}$ animation rather than 2D book formats? During five years of literacy playshop research (Wohlwend, 2011, 2015; Wohlwend, Buchholz, Wessel Powell, Coggin, \& Husbye, 2013), I've worked with preschool, kindergarten, and first grade teachers as well as university teacher education students to develop literacy curricula that include digital filmmaking, animation apps, iPad puppetry, and dramatic play with popular media toys. In this research, children use iPads to produce films with dolls, action figures, and other media toys or with friends in live-action videos on iPads or created digital puppetry (e.g., PuppetPals,) with "cut out" avatar puppets of themselves to star in simple films, animated by multiple hands crowding together on a single touchscreen (Wohlwend, 2015). Video analysis of players' actions and films reveals the complexity in children's co-authored interactive stories on iPads with touchscreens and icon-based apps with minimal print. For example, I recently conducted a study in a preschool classroom that showed how easily-recognized photo puppets of favorite media stories (e.g., Anna, Elsa, and Olaf of Disney's Frozen) enabled children with shared understanding of the media narrative to coordinate character actions 
while touchscreen navigation (e.g., taps, squeezes, swipes) enabled quick revisions to the emerging story (e.g., addition, deletion, sizing, movement of characters). As they played on iPads, these small groups of two or three player-producers negotiated tensions among their individual moves in a fluid action-packed scene and the need to keep friends at the table and maintain their shared play. Children's play moved between onscreen and offscreen action, as children mixed their digital avatars and actual toy figurines, burst into song, recited remembered snippets of dialogue, or imitated characters' voices. In this way, digital technology enabled more cohesive and collaborative moments of storytelling than children could produce with their own handmade puppets or drawings that held little meaning for peers. These findings resonate across my research: when allowed to play and access popular media and technology knowledge as literacy resources and cultural expertise, children used realistic snippets of dialog, elaborately detailed settings, credible character personalities, and logical plot organization similar to their favourite familiar films, television programs, video games, or apps.

Insight \#1: Few researchers capture play with as much zeal as Wohlwend and it shines through her research with young children. What I learned from my visit with Wohlwend is the unconstrained mobility and fluidity children have as they make, play, design, and produce texts and draw on media stories and ecologies to do so. Literacy in this instance is embodied, modally rich and always productive and participatory.

\section{USA: Composing eBooks with iPads and Digital Cameras}

Deborah Rowe, Vanderbilt University, USA

What can touchscreen tablets help teachers and students do that they cannot do easily otherwise? This is a question that my colleagues and I have been exploring in our research (Rowe \& Miller, 2015; Rowe, Miller, \& Pacheco, 2014). We wondered how new technologies like iPads and not-so-new technologies like digital cameras could be used to expand the learning possibilities for 4-year-olds who were learning English as a new language at school, and who were also emergent writers. We wanted to design digital composing opportunities supporting children's use of their heritage languages at the same time they were learning to write and speak English, and that created opportunities for children and families to incorporate their home/community experiences into school literacy activities.

Working with prekindergarten teachers, we invited children to compose eBooks using iPads equipped with writing, drawing, and book-making apps. iPads offer new kinds of opportunities to compose with photos and voice recordings. During eBook composing, we capitalized on these digital features by using images as anchors for conversation and composing, and inviting children to record eBook narrations in both their languages.

For the first several months, we invited children to use the iPad's built-in camera to take photos in the classroom or to draw their own pictures using drawing apps. Once children were familiar with digital composing, on a rotating basis, teachers sent home inexpensive, kid-friendly digital cameras. Children took photos at home, community events, family shopping trips, and much more. Home photos were loaded into the iPad at school and used for eBook composing. Working with children at the iPad center, we adjusted the following participation structure as needed: a) invite children to take a photo 
Preprint

in the classroom, select a photo from home, or draw a picture; b) support photography or drawing; c) engage children in conversation about the image; d) invite children to write a message about the image; e) talk about children's messages or suggest possible messages; f) support emergent writing; g) invite children to record an oral narration in English and their heritage language; h) support oral narration; i) re-view/re-listen/re-read the composition; and j) share the eBook with others. To encourage multilingual composing, we worked with parents and community members to create demonstration eBooks featuring narrations recorded by familiar adults in all the languages spoken in the class.

Our research showed that children easily transferred page-based writing and drawing skills to the touchscreen. As expected, photos provided concrete visual anchors for conversation when teachers and children were not fluent speakers of the same languages. Home photos and multilingual voice recordings allowed children and families to share experiences and languages used outside of school and created culturally relevant texts for use in school instruction. eBook composing provided authentic reasons for writing, and created interested audiences at school and at home. Perhaps most exciting, eBook composing provided an avenue for two-way sharing of expertise, information, and languages between home and school.

Insight \#2: From Rowe I learned about traversing modes to practice different literacy strands. In asking language learners to move from images to words to oral retellings to moving image, Rowe and her team foster flexibility in channels used to make meaning. Add to this the English language learner piece, which to me is a gap in literature in the areas of multiliteracies and digital literacy.

\section{Canada: A is for "App not Apple"}

Anne Burke, Memorial University, Canada

My research study examines how children use technologies to shape their engagements during early childhood. In particular, my research considers what devices they use and how much they use them, culminating into a consideration of how the usage of digital technologies amongst young children affects their development of literacysuch as reading, writing and visual composing. Considering there is a significant research gap regarding the usefulness of digital technologies amongst young children (as well as many fears and stereotypes), this project will shed light on the importance of digital devices in the stimulation of multiliteracies and in particular multimodal aspects of learning. The research comprises mixed methods; case studies along with purposive and convenience sampling; and surveys and statistical data. In essence, this project aims to shed light on the importance of the relationship between children, family, digital technologies, pre-schools and literacy in the modern world.

Considering modern usage of tablets, smartphones, computers, etc. amongst young children is unprecedented, many educators may feel uninformed about the ways children use these technologies. Teachers can integrate digital technologies that children are familiar with, such as tablets, into the classroom setting in order to facilitate children's literacy. More importantly, is the selection of learning apps and literate abilities, which are being developed at home as apart of this early literacy knowledge. We see the research as two-fold, the potential to contribute to children's understanding of 
Preprint

technology and language alike, as well as the teacher's understanding of these in various learning contexts, and the process of engagement. We challenge educators and administrators to rethink traditional modes of teaching, allowing them to integrate not only different ways of thinking into the classroom, but different, globally-oriented ideas; with digital technologies, children and teachers have access to a plethora of ideas, beliefs, cultures, and resources. Younger children are using more videos and images produced at home and in other spaces of play to supplement traditional forms of language arts in schools. Digital tools, alongside traditional early language materials may promote equal opportunities for children of all socio-economic backgrounds. This study celebrates how the usage of digital technology by children is not just for play and amusement - but when used in a collaborative learning approach becomes a new way of thinking about traditional classroom literacy practices in a new and exciting way.

Insight \#3: Burke taught me about the need for teachers and students to have meta-awareness of what technology best suits the literacy task. Technologies cannot be created equal and Burke's research probes deeper into the affordances and constraints of different technologies from tablets to wearable devices to using sound editing software. Taking seriously McLuhan's (1964) 'the medium is the message' the means by which we make meaning is fundamental to what gets expressed and represented and Burke's work animates this belief and makes it a part of the digital literacies experience.

\section{UK: Communication, literacy and diverse technologies}

\section{Rosie Flewitt, UCL Institute of Education}

As a nursery practitioner many years ago, I became fascinated by how different children adapt to the challenges of communicating in this new environment, and how they go about exploring the many activities, books and toys on offer. As my research developed, the 'digital revolution' was reshaping everyday communicative practices, offering new challenges and possibilities for early learning. In a fast-changing communicative landscape, I began to explore how young children growing up in today's world develop a range of communicative and literacy skills across digital and print media. In one study conducted with colleagues Messer and Kucirkova (2015), we worked with children and their teachers to investigate the potential of mobile touch technologies, such as iPads, for early learning in nursery, primary and special education. The teachers in each setting researched suitable apps to support curriculum goals, and then developed a range of carefully planned literacy activities using iPads. These activities ranged from helping children develop specific skills using phonics or spelling apps, to using iPads more creatively to make photographic and video diaries of their indoor and outdoor learning. In this study, we found that incorporating iPads in classroom learning stimulates children's motivation and concentration, enables home and school learning experiences to be brought together, offers rich opportunities for communication, collaborative interaction, independent and enquiry-led learning, and for children to achieve high levels of accomplishment in literacy. One striking finding across the settings was that iPad-enabled literacy activities motivated the reading and writing of children who had previously been reluctant to engage in literacy activities. Although planning the use of iPad-based literacy activities is time-consuming and requires practitioners to 
master technical skills for their effective use, all the teachers we worked with came to value the opportunities iPads offer to deliver curriculum guidelines in new ways, and to give all children equitable access to touch-screen technologies. And guess what? They get children talking too!

Through this work, I have come to understand how contemporary literacy practices require even very young children to make meaning with a highly varied repertoire of signs and symbols across traditional and digital media.

Insight \#4: From Flewitt, I was reminded of my own experience in early years contexts (Rowsell, in press) watching young children move around and engage in sundry literacy activities in early childhood spaces. Like Flewitt, I recognized that some children had learned behaviours with tablets because they had them at home and other children were experimenting with what tablets can do because it was their first time using them. Flewitt succinctly describes how children learn through a spectrum of modes and texts and how agile they are with these varied repertoires of signs and symbols.

\section{UK: Children's Cultural Worlds}

Jackie Marsh, University of Sheffield

About twenty years ago I began to research the cultural interests of young children, exploring how these interests could inform literacy curricula in order to enhance motivation and engagement. My research has consistently followed children's interests and popular cultural practices and, inevitably, as children interests began to focus on digital technologies, I followed them into that area. Charting children's passions in this way means I have studied a rather eclectic range of digital literacy practices over time, including young children's use of virtual worlds, their creation of machinima (e.g. films made in virtual worlds), their viewing of peer-produced videos on YouTube (such as 'unboxing' videos) and, more recently, their use of augmented reality apps. Throughout these projects, I have focused on issues relating to children's voice and agency as they express these through playful and creative activities.

Central to this research has been collaboration with teachers who have a strong understanding of the need to place children and their interests at the centre of the curriculum - a truly 'child-centred' education. That is not to suggest children should be denied access to new and unfamiliar experiences, but that we need to start with an understanding of the child and her or his passions, then find a way to build these into an exciting and challenging literacy curriculum that is both familiar and strange.

An example of this was a project conducted alongside Peter Winter, who was a gifted teacher at Monteney Primary School in Sheffield. Children love to read, talk about and play monsters and so this theme was the centre of a project in which young pupils learned to code using Scratch to create their monster sprites and games, created 3D monsters using CAD software, used websites such as Voki to create and vocalise Monster poems and made monster animations and short films (see the project website for more details). Children came to the sessions full of ideas for their creations from the many monster stories they had seen at home such as the films 'Monsters Inc' and 'Shrek', and the sessions enabled the children to encounter texts they may not have been familiar with, such as Lewis Carroll's poem 'Jabberwocky'. Peter wove both canonical and popular references together in a seamless manner, all the time using as his pedagogical touchstone 
Preprint

the children's own life experiences and interests. Through these means, children developed the kinds of literacy skills so important for the digital age - ablility to read and write traditional print, but also code, edit still and moving images, synch animations with music and so on. Enabling children to share these creations with parents and the wider public through social media sites such as blogs and Twitter was commonplace practice for Peter, thus offering meaningful audiences for the children's work.

Insight \#5: From Marsh, I have consolidated an understanding of taking detailed fieldnotes of children's engagements with texts; the strength of longitudinal work in homes and schools; and of charting children's textual and multimodal pathways.

\section{South Africa: Placing Digital Literacies \\ Mastin Prinsloo, University of Cape Town}

My research engages with questions of how digital media are encountered and used at home, in schools and out of school by children, youths and adults. I am less interested in the design intentions of the makers of digital hardware and software and more interested in what might be called the 'social life' of digital media, the ways that their uses are shaped and distinctive with regard to their embedded uses by situated users in particular settings. I study digital media use by children, youths and teachers as placed resources and I am interested in understanding and attempting to explain variations in their use, particularly by children and teachers who are from social and linguistic minority or non-middle class backgrounds. I see such variations as shaped in particular by the differences that children, youths and teachers of various sorts bring to the use of digital media and differences in what people are up to more broadly when they are using digital media. My research features accounts of individuals and groups who improvise with the technologies that they have and who use these resources in ways that are novel and that in particular cases are sometimes less than successful. Rather than being simply accounts of deficit or disadvantage, however, these studies open up the space for an understanding of how digital media resources are taken hold of in out of school settings and how they work in educational settings.

My recent research along with students and colleagues has included a contrastive study of the uses of digital media at home by children from professional-class and underclass families in South Africa. The research shows that social class differences amongst African children take on globalised cultural dimensions, by way of language practices and online media practices, which sharpen differences between middle-class children and poorer children. The children of professionals absorbed the cultural capital that English language resources, digital hardware and unlimited broad-band connectivity in their home afforded them by way of connections to global middle-class cultural flows. In contrast, the children of unemployed parents living in a shack settlement outside Cape Town played with the Internet-connected cell phones of their parents but such play did not provide any access to more global resources of information and entertainment, partly because the children did not share the sociocultural backgrounds or linguistic resources that are typically taken-for-granted on websites designed for children and partly because the parents saw little point in allowing their children free access to play with digital resources. 
Preprint

Insight \#6: Prinsloo has carved out a niche in digital literacies for situating and uncovering instantiated ideologies in digital literacies like social class, race, culture, power which give us pause to think about differential access and taken for granted notions about who has and who does not have technologies.

\section{Australia: Indigenous Ways of Literacy in Digital Literacies Around the World Kathy Mills, Queensland University of Technology}

Over the past three years, I have been greatly inspired by participatory community research with the Yuggera Indigenous school community of South East Queensland. Foundational to my approach with Indigenous communities in Australian is a recognition that language and literacy practices are deeply interconnected with the epistemologies and ontologies of cultures. Language and how it is used and taught is not value neutral: it is integral to one's view of knowledge, identity and beliefs. This perspective seeks to illuminate cultural frames of reference for literacy practices, recognizing the different value ascribed to diverse language forms, extending beyond written words to - for example - the somatic or bodily forms of meaning that are communicated through Indigenous dance (Mills, 2016).

Together with the Indigenous principal and teachers, we are exploring Indigenous ways to multimodal and digital literacy that embed the valued epistemologies, the beliefs about knowledge, of the Yuggera people. Central to the multimodal literacy approach with this community is building strong, transgenerational relationships between the Indigenous elders, Indigenous teachers and the students, as valued knowledge is passed on from past to future generations through language and digital heritage practices. Digital heritage practices, such as recording ancestral dreaming stories, have also become a vital part of sustaining the stories, values and knowledge of Indigenous peoples in the Yuggera language region (Mills, 2014).

Distinctive features of this approach to teaching literacy practices is the integration of Aboriginal and Torres Strait Islander artwork, music (e.g. didgeridoo, Indigenous language songs, body paints), history, local Indigenous languages, dance, and rituals such as yarning circles. The students participate in contemporary digital text production activities such as digital storytelling, video, blogging, and e-book creation, among many other reading and writing practices. The digital stories share Indigenous narratives and knowledge at school events, including sharing beyond the school to outreach to other educational and community networks.

Key knowledge themes in the teachers' literacy units have included Indigenous sacred spaces, connections to places, birth totems - connections to animals of significance to Indigenous people, dreamtime stories or lore, Indigenous humor, Indigenous pride, and perspectives of the early colonization of Australia and land rights. Indigenous schooling is successful when the students develop a strong sense of their Indigenous cultural identities, and multimodal communication is a vibrant part of this Indigenous community.

The preparatory and year one students (age 5-6 years) listened to stories told by an Indigenous elder who visited the classroom. Each child selected an Aboriginal dreamtime story connected to their personal birth totem. After learning about their totem and relevant dreamtime story, the students retold it using drawings and handwritten 
words on paper that the teacher photographed. With adult assistance, the students used online Smilebox software to present their digital stories as musical e-scrapbooks (Mills, 2014). While these five-year olds enjoyed the novelty of the task, more importantly, they were able to articulate the significance of these stories to their Indigenous family, community and people.

Mikayla, an Aboriginal teacher of students in the middle elementary years, taught the students how to write poetry about the first white contacts during the early colonizing of Indigenous peoples of Australia. The Year 5 class (students age 9-10 years) began by reading and researching Indigenous land ownership. The students wrote poetry that provided alternative perspectives of these laws as the original custodians of the land. The students used the iPad Tellegami application to audio record their poetry recitations, which involved automated lip-syncing by a personalized avatar. They took photographs of original Indigenous artwork and photos of the landscape to create backgrounds for the animated poetry recitation (Mills \& Exley, 2015).

The literacies of the dominant, Eurocentric societies that are typically emphasized and normalized in school curriculum and assessment are value-laden, whether constructed with or without digital media. The enactment of digital literacy practices across cultures needs to align with, and flow from, the dynamic ways of knowing and making meaning of communities. What is needed is reflection on the historical and contemporary valued knowledge and identities of the community - the epistemic and ontological frames of reference - that can usefully guide both how and what children practice as digital literacy at school both today and for the future.

Insight \#7: From Mills I got an in-depth perspective of technology as a lived practice shaped around culture and social practices. Working with aboriginal families and educators, Mills considers how technology affords greater expression of meanings and stories by asking children and adults to combine modes (e.g., moving images, words, and animation) on-screen to share narratives. Mills reveals the meaning-making potential of technologies like iPads by using apps to design narratives and taking advantage of the participatory nature of tablets to share stories and reflections.

\section{China: Cross-Locale Trips to Get Out of Information Filter Bubbles:} A (Cross-Cultural) Digital Literacy Training Curriculum

Han-Teng Liao, United Nations University Institute on Computing and Society, 1 Macau; and Angel Lin, University of Hong Kong

Note: UNU-CS is a new research institute at the intersections of information and communication technologies and international development (ICTD) focusing on the key challenges faced by developing societies through high-impact innovations in computing and communication technologies. UNU-CS is nurturing three inaugural research Labs: Digital Peace Lab, Gender Tech Lab, Small Data Lab.

The technical notion of "locale" in computing refers to a set of parameters that defines the user's language, region and other preferences such as language scripts. The theoretical notion of "locale" in social theories, on the other hand, refers to "the use of space to provide the settings of interaction, the settings of interaction in turn being essential to specify its contextuality" (Giddens, 1986, p. 118). Integrating these two senses of the word "locale", we argue that a set of practical knowledge, surrounding the ways in which "locales" shape our digital networked experience should be integrated into 
Preprint

the school curriculum in a systematic way to help both teachers and students first to recognize the existence of 'information filter bubbles', then to understand the underlying mechanism, and finally to embark on what we called "cross-locale" digital trips by switching one's locale settings on one's computer. Based on working knowledge that can be followed and practiced by everyday Internet users, we propose a digital literacies curriculum that includes the following components: (1) country codes, language codes, and language tags: understanding the global regime of country, language and locale recognition in the digital networked environment, (2) website, software and content localization and internationalization business and practices, and (3) new skills for individual users to switch between locales to experience different use of online space that are specified by its country and language context. The concept component should deliver the role of languages and countries in setting interactions online.

The skill component should deliver the technical and social skills for users to switch such settings in the browsers, major online platforms, etc. The curriculum should help young students to be aware of, and act upon these "settings of interaction" to foster multilingual, cosmopolitan learning and thinking. It will contribute to the efforts to make 'think global, act local' more than just a slogan but an everyday cross-cultural, multilingual, digital experience and practice. The ways in which the proposed curriculum can be implemented and evaluated are also being investigated.

Insight \#8: From Liao and Lin I acquired an appreciation for students to apply mobility and spatiality skills within literacy teaching and learning. That is, ask students to think global and act local by having students set their devices on different geographies and to think in relation to the different geography and then contrast it with their local community.

\section{Taking Stock of My Travels}

After travels to different digitally informed literacy research sites, though there is a need to resist static, rigid notions of digital literacies that start to recede into autonomous models, we also need generative terms and conceptual frameworks to yoke onto planning lessons and units and conducting research on, with, and about technology. Gone are the days that we can deny that digital literacies are pretty much the same as print literacies. Gone are the days of ignoring differential access to technologies. And, I think, gone are the days that digital literacies are rendered generic. But, are there helpful, practical insights to help literacy teachers?

Captured in Table 1 are some of the lessons that I have learned with possible concepts that inform each researcher lesson. 
Preprint

Table 1: Generative Terms and Concepts

\begin{tabular}{|c|c|c|}
\hline Term & Concept & Literacy Skills \\
\hline Glocal Play & $\begin{array}{l}\text { Fostering cosmopolitan } \\
\text { dispositions by existing in } \\
\text { the global while living in } \\
\text { the local }\end{array}$ & $\begin{array}{l}\text { Reading, Writing, } \\
\text { Representing, Coding, } \\
\text { Visualizing, and Meta- } \\
\text { Linguistic Awareness }\end{array}$ \\
\hline Multimodal Narratives & $\begin{array}{l}\text { Designing and producing } \\
\text { multimodal stories that } \\
\text { involve three or more } \\
\text { modes }\end{array}$ & $\begin{array}{l}\text { Viewing, Representing, } \\
\text { Mapping, Editing, Talking } \\
\text { and Writing }\end{array}$ \\
\hline Online \& Offline Curation & $\begin{array}{l}\text { Gathering information } \\
\text { across different text genres } \\
\text { and sources to produce a } \\
\text { text }\end{array}$ & $\begin{array}{l}\text { Reading, Writing, } \\
\text { Viewing, and Summarizing }\end{array}$ \\
\hline Converged Remix & $\begin{array}{l}\text { Combining texts to display, } \\
\text { juxtapose, or blend them } \\
\text { into another text }\end{array}$ & $\begin{array}{l}\text { Reading, Viewing, Editing, } \\
\text { and Visualizing }\end{array}$ \\
\hline Material Connections & $\begin{array}{l}\text { Making meanings from } \\
\text { media sources through } \\
\text { different sets of materials }\end{array}$ & $\begin{array}{l}\text { Visualizing, Editing, } \\
\text { Reading, and Writing }\end{array}$ \\
\hline Modal Choice & $\begin{array}{l}\text { The art of finding the right } \\
\text { mode to design and } \\
\text { produce with the right } \\
\text { technology }\end{array}$ & $\begin{array}{l}\text { Viewing, Visualizing, } \\
\text { Mapping, Writing, and } \\
\text { Talking }\end{array}$ \\
\hline
\end{tabular}

Thinking across the postcard vignettes above there are vestiges of all of these terms and concepts. Glocal play (Luke \& Carrington, 2004) figures largely in so many of them: Prinsloo's excavation of the affordances of technologies; Liau and Lin's efforts to insist on more of a cosmopolitan look at digital literacies by existing in other localities in global cyberspace; and, Mills' culturally infused multimodal research in aboriginal communities. All of these studies put people and places at the heart of digital literacies. Every vignette is multimodal: Flewitt pushes educators and researchers to create synchronized children's multimodal sensibilities with formal learning; Burke reminds us to be aware of what technologies offer and to complicate their use and applications. All of the vignettes entangle online and offline worlds: Marsh and Wohlwend have illustrated for years that children move fluidly between virtual and physical worlds and they do so comfortably and enthusiastically. It is clear from each researcher that digital texts and technologies seldom exist in solitude, rather they are converged with other texts (e.g., through hyperlinks or with embedded videos) or technologies (a 'smart phone' is far more than a phone - it has apps, a camera, a calendar, an alarm clock, etc). Many of the vignettes depict the close relationship between reading and writing or reading and designing/production: Rowe captures multimodal repertoires in-play as language learners materialize stories on iPads. Finally, and most importantly in my view, all eight researchers remind us that there are always two or more modes involved in literacy work and how essential it is to choose the right mode to privilege for a text. This column, 
Preprint

hopefully, goes some way in nuancing the term as a move to change the conversation to more grounded interpretations of digital literacies.

\section{Acknowledgements}

I would like to thank Dr. Cathy Burnett of Sheffield Hallam University for her helpful feedback as I wrote my first column as Digital Literacies Department Editor.

\section{References}

Ellsworth, E. (2005). Places of learning: Media, architecture, pedagogy. . New York, NY: Routledge Falmer.

Flewitt, R.S., Messer, D., \& Kucirkova, N. (2015). New directions for early literacy in a digital age: The iPad. Journal of Early Childhood Literacy, 15(3), 289-310.

McLuhan, M. (1964). Understanding media: The extensions of man. Cambridge, MA: The MIT Press.

Giddens, A. (1986). The constitution of society: Outline of the theory of structuration. Oakland, CA: University of California Press.

Luke, A., \& Carrington, V. (2004). Globalisation, literacy, curriculum practice. In T. Grainger (Ed.), The Routledge Falmer reader in language and literacy (pp. 5266). New York: Routledge Falmer.

Mills, K.A. (2014). Cultural flows in an Aboriginal school: Deterritorializing textual production through a socially mediated Indigenous heritage. In American Educational Research Association Annual Meeting: The Power of Education Research for Innovation in Practice and Policy, 3-7 April 2014, Philadelphia, Pennsylvania, USA.

Mills, K.A. (2016). Literacy theories for the digital age: Social, critical, multimodal, spatial, material and sensory lenses. Bristol, UK: Multilingual Matters.

Mills, K.A. \& Exley, B.E. (2015). Decolonizing digital heritage practices for Indigenous literacy: A multimodal analysis of iPad Tellagami videos. In AERA 2015 Annual Meeting: Toward Justice: Culture, Language, and Heritage in Education Research and Praxis, 16-20 April 2015, Chicago, Illinois.

Prinsloo, M. (2005). The new literacies as placed resources. Perspectives in Education, 23(4), 87-98. 
Preprint

Rowe, D.W., \& Miller, M.E. (2015). Designing for diverse classrooms: Using iPads and digital cameras to compose eBooks with emergent bilingual/biliterate four year olds. Journal of Early Childhood Literacy. doi:DOI: 10.1177/1468798415593622

Rowe, D.W., Miller, M.E., \& Pacheco, M.B. (2014). Preschoolers as digital designers: Composing dual language eBooks using touchscreen computer tablets. In R.S. Anderson \& C. Mims (Eds.), Handbook of research on digital tools for writing instruction in K-12 settings (pp. 279-306). Hershey, PA: Information Science Reference.

Rowsell, J. (in press). Be the 'I' in iPad: iPads and the children who love them. In D. Harwood (Ed.), Crayons and iPads: Learning and teaching of young children in the digital world. London: Sage.

Wohlwend, K.E. (2011). Playing their way into literacies: Reading, writing, and belonging in the early childhood classroom. New York, NY: Teachers College Press.

Wohlwend, K.E. (2015). One screen, many fingers: Young children's collaborative literacy play with digital puppetry apps and touchscreen technologies. Theory into Practice, Special Issue on Digital Media and Learning.

Wohlwend, K.E., Buchholz, B.A., Wessel-Powell, C., Coggin, L.S., \& Husbye, N.E. (2013). Literacy playshop: New literacies, popular media, and play in the early childhood classroom. New York, NY: Teachers College Press. 